OPEN ACCESS

Edited by:

Luis A. Martinez-Lemus, University of Missouri, United States

Reviewed by:

Pooneh Bagher, Texas A\&M University, United States

Erik Josef Behringer, Loma Linda University, United States

*Correspondence: Geoffrey P. Dobson geoffrey.dobson@jcu.edu.au

Specialty section: This article was submitted to Vascular Physiology a section of the journal Frontiers in Physiology

Received: 04 July 2017 Accepted: 06 October 2017 Published: 20 October 2017

Citation:

Dobson GP, Arsyad A and Letson HL (2017) The Adenosine Hypothesis Revisited: Modulation of Coupling between Myocardial Perfusion and Arterial Compliance.

Front. Physiol. 8:824. doi: 10.3389/fphys.2017.00824

\section{The Adenosine Hypothesis Revisited: Modulation of Coupling between Myocardial Perfusion and Arterial Compliance}

\author{
Geoffrey P. Dobson ${ }^{1 *}$, Aryadi Arsyad ${ }^{2}$ and Hayley L. Letson ${ }^{1}$ \\ ${ }^{1}$ Heart, Trauma and Sepsis Research Laboratory, College of Medicine and Dentistry, James Cook University, Townsville, \\ QLD, Australia, ${ }^{2}$ Physiology Department, Medical Faculty, Hasanuddin University, Makassar, Indonesia
}

For over four decades the thoracic aortic ring model has become one of the most widely used methods to study vascular reactivity and electromechanical coupling. A question that is rarely asked, however, is what function does a drug-mediated relaxation (or contraction) in this model serve in the intact system? The physiological significance of adenosine relaxation in rings isolated from large elastic conduit arteries from a wide range of species remains largely unknown. We propose that adenosine relaxation increases aortic compliance in acute stress states and facilitates ventricular-arterial (VA) coupling, and thereby links compliance and coronary artery perfusion to myocardial energy metabolism. In 1963 Berne argued that adenosine acts as a local negative feedback regulator between oxygen supply and demand in the heart during hypoxic/ischemic stress. The adenosine VA coupling hypothesis extends and enhances Berne's "adenosine hypothesis" from a local regulatory scheme in the heart to include conduit arterial function. In multicellular organisms, evolution may have selected adenosine, nitric oxide, and other vascular mediators, to modulate VA coupling for optimal transfer of oxygen (and nutrients) from the lung, heart, large conduit arteries, arterioles and capillaries to respiring mitochondria. Finally, a discussion of the potential clinical significance of adenosine modulation of VA coupling is extended to vascular aging and disease, including hypertension, diabetes, obesity, coronary artery disease and heart failure.

Keywords: rat aorta, adenosine, relaxation, ventricular-arterial coupling, vasodilation, compliance

From these studies emerged the idea that a labile substance was released from the heart (presumably from the myocardial cells) when the oxygen supply became inadequate for the oxygen needs of the heart, and the labile substance dilated the coronary-resistance vessels, thereby increasing coronary blood flow and restoring the balance between oxygen need and supply.

Robert M. Berne (originator of the "Adenosine Hypothesis"). Quoted from (Berne, 1998), p14

\section{BACKGROUND}

Berne's "labile substance" was adenosine, and the same "adenine compound" was shown to influence heart function some 30 years earlier by Drury and Szent-Gyorgyi (1929). Today, we know adenosine as a naturally occurring, multi-functional, endogenous purine nucleoside that plays a key role in the cardiovascular system by activating adenosine receptor subtypes on constituent 
cardiac and vascular cells: $\mathrm{A}_{1}, \mathrm{~A}_{2 \mathrm{~A}}, \mathrm{~A}_{2 \mathrm{~B}}$, and $\mathrm{A}_{3}$ (VintenJohansen et al., 1999; Fredholm et al., 2001; Linden, 2001; Jacobson and Gao, 2006; Leal et al., 2008; Headrick et al., 2013). Adenosine also regulates cardiovascular function indirectly from its effects on central and peripheral nervous systems (Minic et al., 2015). Adenosine is produced by most cells in the body in response to metabolic stress or injury and also assists in the modulation of the early inflammatory and innate immune responses (Hasko and Cronstein, 2004; Headrick et al., 2013). Adenosine has been shown to inhibit the release of proinflammatory cytokines TNF- $\alpha$, IL-6, and IL-12, and stimulate the release of anti-inflammatory cytokines IL-8, IL-10, and VEGF by macrophages, and there is accumulating evidence that it promotes angiogenesis, tissue remodeling and wound healing (Hasko and Cronstein, 2004; Chan and Cronstein, 2010; Ernens et al., 2015; Vecchio et al., 2017). The focus of this perspective is on a new role for adenosine as a possible "aortic compliance regulator" that links myocardial perfusion to arterial compliance in the cardiovascular system.

\section{THE ADENOSINE HYPOTHESIS: METABOLIC CONTROL OF CORONARY BLOOD FLOW}

Since Berne first proposed the "adenosine hypothesis" over 50 years ago (Berne, 1963, 1980), there has been much controversy about its wider importance to the regulation of coronary flow in heart, and other organs in normal and pathological states (Collis, 1989; Feliciano and Henning, 1999; Feigl, 2004). Berne originally proposed that during hypoxia (or ischemia) adenosine was a potent local negative feedback regulator between myocardial oxygen supply and oxygen demand. As myocardial $\mathrm{pO}_{2}$ decreases during hypoxia (i.e., increased oxygen demand), adenosine is formed in the myocyte from the breakdown of adenosine $5^{\prime}$ monophosphate (AMP), diffuses across the interstitial space to the coronary artery and causes vasodilation (i.e., increased oxygen supply) (Figure 1). Berne's hypothesis was bold and far-reaching because during the 1960s there was little or no knowledge on the mechanisms of how adenosine dilated the vessel wall.

In the late 1970s the "adenosine hypothesis" entered a new era when adenosine receptors were identified and functionally characterized (Fredholm et al., 2001; Linden, 2001; Jacobson and Gao, 2006). A decade later Headrick and Berne showed that adenosine dilation of guinea-pig aorta involved activation of the adenosine $\mathrm{A}_{2}$ receptor subtype, with $30 \%$ relaxation being derived from the endothelium and $70 \%$ from underlying smooth muscle (Headrick and Berne, 1990). Today, coronary vasodilation involves principally the activation of $\mathrm{A}_{2 \mathrm{~A}}$ or $\mathrm{A}_{2 \mathrm{~B}}$ receptors depending upon animal species, and a complex crosstalk between $A_{1}$ and $A_{3}$ receptor subtypes that remain poorly defined (Headrick et al., 2013). Notwithstanding the advances in the 1990s, in a memoir written by Berne at the turn of the century, he jokingly wrote about the ongoing controversies surrounding his "adenosine hypothesis":

"But the worst blow was when I was skiing with Larry Rowell and
Eric Feigl and some of their postdocs on one of my many visits to
Seattle. As I lost control on a steep slope and proceeded to crash, a
voice rang out from one of the postdocs on the ski-lift as he viewed
the carnage... There goes the adenosine hypothesis." (Berne, 1998, p. 14).

Since that time increasing support has accrued for the concept that adenosine acts as a "negative feedback regulator" in most tissues during hypoxia/ischemia, including skeletal muscle and brain (Feigl, 2004). In addition, adenosine has many other important cellular protective properties following hypoxia/ischemia or injury (see Background above). More recently, adenosine has been identified as one of the self-preservation signals of ischemic preconditioning and post-conditioning in the heart and most organs of the body, which appears to involve a memory-like function leading to the activation of multiple survival kinase pathways (VintenJohansen et al., 2007; Headrick et al., 2013). Notwithstanding the evolutionary importance of adenosine to flow regulation and energy metabolism, it must be acknowledged that adenosine is only one of many vascular modulators that link blood flow supply to metabolic demand. Other modulators include membrane potential, nitric oxide $(\mathrm{NO}), \mathrm{K}_{\mathrm{ATP}}$ channel openers, catecholamines, endothelins, prostanoids, opioids, reactive oxygen species, $\mathrm{pO}_{2}, \mathrm{pCO}_{2}$, and $\mathrm{pH}$ (Furchgott, 1983; Wilkinson et al., 2002; Duncker and Bache, 2008; Bellien et al., 2010; Marti et al., 2012; Quillon et al., 2015; Félétou, 2016; Behringer, 2017).

\section{PHYSIOLOGICAL FUNCTIONS OF THE LARGE ELASTIC AORTA}

A large number of experimental studies spanning over three decades have demonstrated that adenosine is a potent vasorelaxant of thoracic aortic rings from a wide range of species (Heistad et al., 1978; Lewis and Hourani, 1997; Ray and Marshall, 2006; Mustafa et al., 2009; Ponnoth et al., 2009; Headrick et al., 2013; Arsyad and Dobson, 2016). An important question that is rarely asked, however, is how does relaxation of an isolated aortic ring translate into function in the intact system? And why has adenosine signaling been selected and highly conserved in the thoracic aorta? To help answer these questions, we will first consider the functional differences between the aorta and smaller muscular arterioles. The aorta operates as a biological "windkessel" or buffering reservoir that stores a portion $(\sim 10 \%)$ of kinetic energy from stroke work during systole, and transfers it during diastole to maintain a relative constant pressure and flow to the periphery (London, 2005; Erbel and Eggebrecht, 2006; Steppan et al., 2011). Thus the aorta is not a resistance vessel constantly dilating and relaxing, like the smaller muscular coronary arteries or peripheral arterioles, to meet the oxygen demands of a tissue. The aorta and other conduit arteries (carotid, iliac, pulmonary trunk and brachiocephalic trunk), are highly elastic vessels that dampen the pulsatile flow generated 


\section{Berne's 1963 'Adenosine Hypothesis' of Coronary Blood Flow Control}

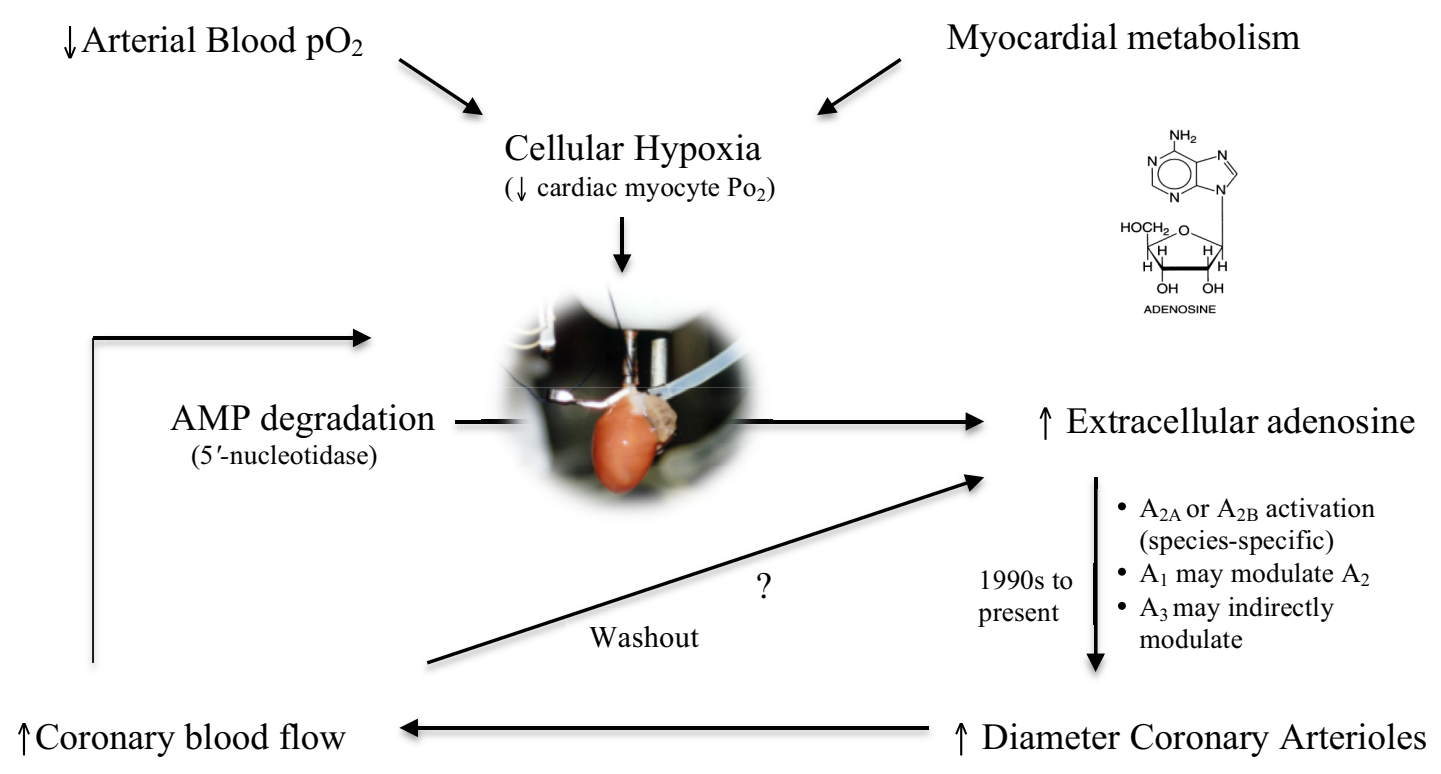

Adenosine is a key mediator of hypoxic/ischemic-induced vasodilation

FIGURE 1 | Schematic of Berne's "adenosine hypothesis," which proposes that myocardial hypoxia leads to the breakdown of adenine nucleotides and formation of adenosine, which "diffuses out of the cell and reaches the coronary arterioles via the interstitial fluid and produces arteriolar dilation" (Berne, 1963). As blood flow increases and metabolic energy demand is met, adenine nucleotides decrease leading to decreases in interstitial adenosine "by washout and enzymatic destruction" (Berne, 1963). In this way, adenosine serves as a local negative feedback regulator of oxygen supply and oxygen demand in the heart.

by heart contractions to ensure an almost continuous flow of oxygenated blood to the periphery (AlGhatrif and Lakatta, 2015).

Elastic arteries are therefore highly compliant, a property not associated with smaller muscular arterioles (Marti et al., 2012). Compliance is defined as the ability of an artery to expand in response to pressure changes (Table 1). The degree of elasticity is contingent upon three main factors: (1) differences in elastin-to-collagen fiber ratios along the vessel, (2) differences in endothelium-smooth muscle responses to cell stretch as a result of stroke work, and (3) differences in sympathetic nerve innervation affecting wall properties (Ooi et al., 2008; Steppan et al., 2011; Marti et al., 2012; Zhipeng et al., 2014). Put simply, compliance is the ability of a vessel to stretch, hold volume and release it during the cardiac cycle. It is directly related to distensibility and inversely related to stiffness (Table 1). The more distal muscular arteries, such as the femoral artery, are less distensible from having a lower elastin-to-collagen ratio compared to the aorta (Zieman et al., 2005; Quinn et al., 2012). Interestingly, arterial compliance and distensibility are inversely related to heart rate, with a higher heart rate having a stiffening effect on elastic arteries, and little effect on muscular arteries (Mangoni et al., 1996). In addition, compliance is known to influence coronary blood flow, an idea first proposed by Bouvrain and Levy (1981).

\section{THE ADENOSINE VENTRICULAR-ARTERIAL (VA) COUPLING HYPOTHESIS}

In contrast to the relationship between myocardial adenosine production and coronary artery perfusion, we propose a different role for adenosine in the thoracic aorta. We propose that adenosine may facilitate coupling between left ventricular output and the ability of the arterial system to receive the blood by modulating aortic compliance (Figures 2A,B). This transfer function is termed ventricular-arterial (VA) coupling, and is the ratio of arterial elastance to left-ventricular elastance (Table 1) (Suga et al., 1993; Chen et al., 2001; Najjar et al., 2004; Chantler et al., 2008; Guarracino et al., 2013). VA coupling has consistently been shown to be a reliable and effective index of cardiovascular performance to maintain oxygen supply to respiring mitochondria (Najjar et al., 2004; Chantler et al., 2008; Guarracino et al., 2013). When this coupling ratio is close to unity, the efficiency of the system is considered to be optimal, and during acute and chronic altered hemodynamic states, such as low cardiac output, the ratio becomes less than one (Table 1). The VA coupling ratio also reflects cardiac energetics, and the balance between myocardial oxygen consumption and mechanical energy required to perform cardiac work (stroke work times heart rate) 
TABLE 1 | Definitions of key terms and methodologies.

\begin{tabular}{ll}
\hline Parameter & Definition \\
\hline $\begin{array}{l}\text { Compliance } \\
(\mathrm{C})(\mathrm{ml} \times\end{array}$ & $\mathrm{C}=\frac{\Delta \text { Blood Volume }}{\Delta \text { Blood Pressure }}$ \\
$\left.\mathrm{mmHg}{ }^{-1}\right)$ & \\
& \\
& \\
Ventricular- & $\mathrm{VA}=\frac{\text { Arterial Elastance }}{\mathrm{LV} \text { Elastance }}$ where \\
Arterial (VA) & $\mathrm{LV}=$ Left ventricular \\
Coupling &
\end{tabular}

Arterial $\quad \mathrm{Ea}=\frac{\mathrm{ESP}}{\mathrm{SV}}, \mathrm{mmHg} / \mathrm{ml}$

Elastance (Ea) $\quad$ ESP $=$ LV end-systolic pressure $=[2 \times$ (systolic BP + diastolic $\mathrm{BP})] / 3$ where BP is blood pressure or $\mathrm{ESP}=0.9 \times$ systolic BP SV, stroke volume 0.9 is a factor that accounts for ESP occurring slightly after peak systolic BP

\section{Physiological \\ significance}

An "index of elasticity" of large conduit arteries. Compliance is directly related to "distensibility," and inversely related to stiffness and elastance (see Ea below). The endothelium because of its capacity to modulate smooth muscle tone modulates compliance

A measure of mechanical efficiency of the cardiovascular system from assessing the interactions between heart performance and vascular function. When $\mathrm{Ea} / \mathrm{Ees}=1.0$, the efficiency of the system is optimal meaning that the left ventricle is providing sufficient SV at its lowest possible myocardial energy consumption. When Ea/Ees $<1.0$ (hypoxia, ischemia, shock, sepsis, traumatic brain injury) efficiency is decreased

An arterial index that estimates the capability of the arterial vessels to increase pressure when stroke volume increases. Ea is a measure of the total arterial afterload on the heart including arterial wall stiffness, compliance and outflow vascular resistance, and systolic and diastolic time intervals. Thus, Ea lumps the steady and pulsatile components of the arterial load into a single number

Ees is a load-independent index of LV contractility. Index also takes into account stiffness, compliance, fibrosis, contraction synchrony and geometric LV chamber dimensions. Ees is an integrated measure of LV systolic performance to pump blood into the arterial tree and does not change substantially with changes in heart rate

PWV is inversely related with $\mathrm{BP}$, and is higher as arteries become stiffer
TABLE 1 | Continued

\begin{tabular}{|c|c|c|}
\hline VA-coupling & Methodologies & $\begin{array}{l}\text { Comments and } \\
\text { references }\end{array}$ \\
\hline $\begin{array}{l}\text { Invasive } \\
\text { "Direct" } \\
\text { method }\end{array}$ & $\begin{array}{l}\text { Left ventricular pressure-volume } \\
\text { (PV) loops. Ea (see above). Ees is } \\
\text { the slope of the end-systolic PV } \\
\text { relationship. End-systolic PV } \\
\text { relationship assumes } \\
\text { independent of load, and that } \\
\text { slope is linear }\end{array}$ & $\begin{array}{l}\text { Suga et al., 1993; Chantler } \\
\text { et al., 2008; Guarracino } \\
\text { et al., } 2013\end{array}$ \\
\hline $\begin{array}{l}\text { Non-invasive } \\
\text { Method }\end{array}$ & $\begin{array}{l}\text { Echocardiographic assessment } \\
\text { of LV end-diastolic and } \\
\text { end-systolic areas, and blood } \\
\text { pressures. Ea (see right). A single } \\
\text { beat measure of Ees is } \\
\text { calculated from ESP/ESV and } \\
\text { assumes Vo is zero }\end{array}$ & $\begin{array}{l}\text { The non-invasive ESP } \\
\text { method for Ea or Ees } \\
\text { accurately predicts LV PV } \\
\text { loop measurements of ESP, } \\
\text { as does the ESP/ESV ratio } \\
\text { Chen et al., 2001; Najjar } \\
\text { et al., 2004; Chantler et al., } \\
\text { 2008; Guarracino et al., } \\
\text { 2013. }\end{array}$ \\
\hline
\end{tabular}

to propel blood forward to the periphery (Chen et al., 2001; Najjar et al., 2004; Chantler et al., 2008; Guarracino et al., 2013).

This new "compliance" role for adenosine may apply to both beat-to-beat cycling during normal cardiac work transitions and acute stress conditions such as during ischemia, stroke, hemorrhagic shock, and other trauma states (Figures 2A,B). In a porcine model of hemorrhagic shock, Jonker and colleagues reported that the thoracic aorta decreases in diameter by $40 \%$ and pulsatility decreases by $62 \%$ during blood loss compared to baseline (Jonker et al., 2011).

In the thoracic aorta, adenosine may operate upstream of other compliance regulators, such as NO (Ray and Marshall, 2006; Quillon et al., 2015). Endothelium-derived NO has been shown to regulate the elastic properties of conduit arteries, and wave profiles, by increasing vascular smooth muscle relaxation (Wilkinson et al., 2002; Bellien et al., 2010; Marti et al., 2012). We recently extended these studies and showed that adenosine's ability to dilate isolated rat thoracic aortic rings involved endothelial NO and a complex interplay between smooth muscle $A_{2 a}$ subtype and voltage-dependent $\mathrm{K}_{\mathrm{v}}$, SarcK $\mathrm{K}_{\mathrm{ATP}}$, and MitoK $\mathrm{K}_{\mathrm{ATP}}$ channels (Arsyad and Dobson, 2016). A possible upstream scenario in the thoracic aorta is that adenosine may bind to one or more endothelial G-protein coupled receptors (e.g., $\mathrm{A}_{2 \mathrm{~A}}$ ), increase cytosolic $\mathrm{Ca}^{2+}$, activate endothelial NO synthase and thereby produce NO. At the same time, increased cytosolic $\mathrm{Ca}^{2+}$ may activate small- and intermediate-conductance activated $\mathrm{K}^{+}$channels to produce endothelium-dependent membrane hyperpolarization (EDH) (Félétou and Vanhoutte, 2007; Shimokawa and Godo, 2016; Behringer, 2017). Adenosine, NO and EDH may work in concert to relax the underlying smooth muscle and increase arterial compliance.

The cardiovascular significance of vasoactive drugs changing smooth muscle tone of the elastic aorta was recognized by Bank (1997) when he wrote:
Propagation speed of the wave along the large arteries
Pulse wave
velocity (PWV) 


\section{A Adenosine and its receptors in the cardiovascular system}

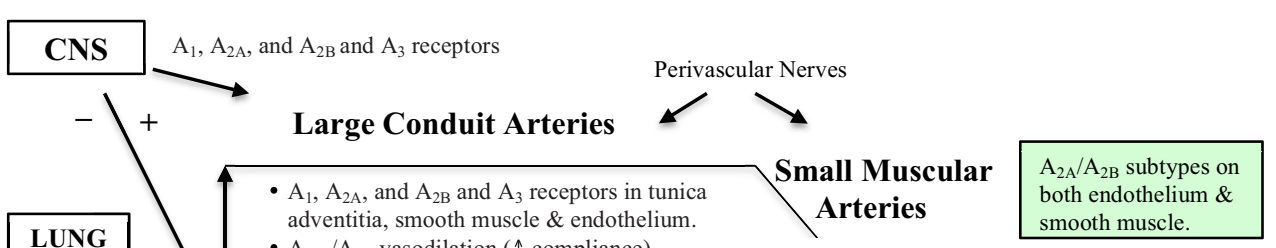

- $A_{2 A} / A_{2 B}$ vasodilation $(\uparrow$ compliance).

- $\mathrm{A}_{1}, \mathrm{~A}_{2 \mathrm{~A}}, \mathrm{~A}_{2 \mathrm{~B}}$ and $\mathrm{A}_{3}$

- $\mathrm{A}_{2 \mathrm{~A}} / \mathrm{A}_{2 \mathrm{~B}}$ vasodilation smooth muscle.

- High abundance of $\mathrm{A}_{3}$

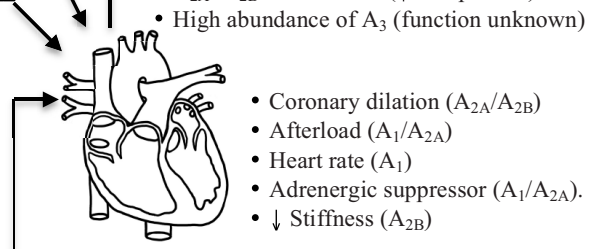

$\left(\mathrm{A}_{1}, \mathrm{~A}_{2 \mathrm{~A}}\right.$, and $\mathrm{A}_{2 \mathrm{~B}}$ and $\left.\mathrm{A}_{3}\right)$

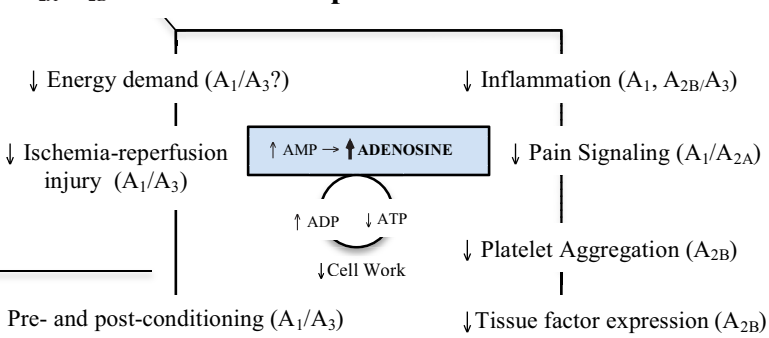

\section{Venous Return}

Adenosine relaxes isolated veins

- $\mathrm{A}_{2}$ mediated (adenosine also

inhibited sympathetic contraction)

- $A_{1}$ and $A_{3}$ receptors also present. $\uparrow$ Wound healing $\left(\mathrm{A}_{1}, \mathrm{~A}_{2 \mathrm{~A}}, \mathrm{~A}_{2 \mathrm{~B}}\right)$

\section{Peripheral Tissues}

Tissue-specific differences in AR's abundance, distribution \& function

\section{B The Adenosine 'Ventricular-Arterial Coupling' hypothesis}

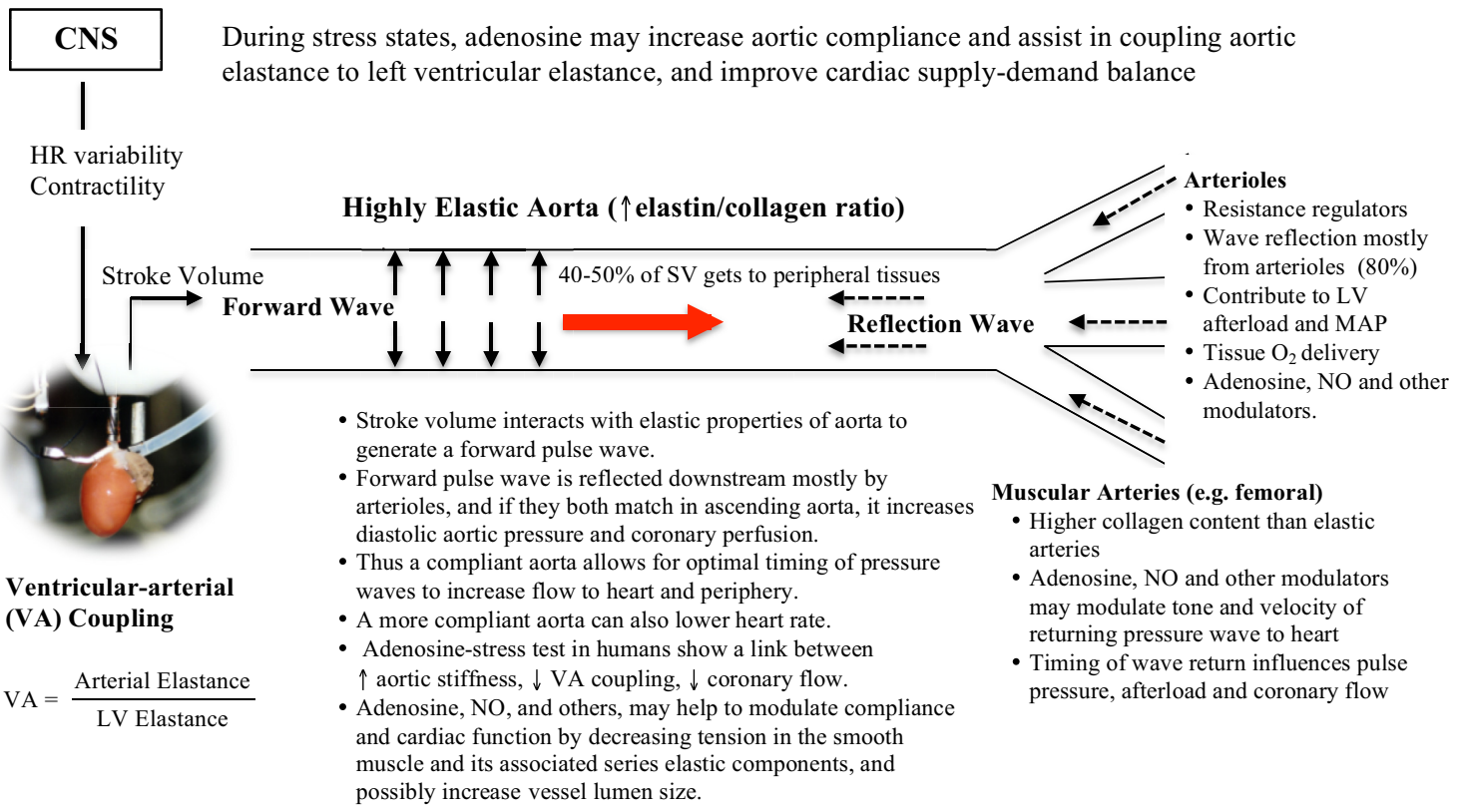

FIGURE 2 | (A) Schematic of adenosine's ubiquitous distribution in the cardiovascular system. Adenosine receptors are coupled to G-proteins with diverse functions. Adenosine is formed and released from most active cells when they are metabolically stressed. In the rat thoracic aorta all adenosine receptor subtypes are located in the three layers of the vessel wall. The physiological significance of adenosine relaxation in large conduit arteries remains largely unknown. Data was obtained from the literature (Fredholm et al., 2001; Tabrizchi and Bedi, 2001; Jacobson and Gao, 2006; Leal et al., 2008; Headrick et al., 2013; Minic et al., 2015). (B) The adenosine Ventricular-Arterial (VA) coupling hypothesis proposes a link between adenosine, arterial compliance, stiffness and beat-to-beat coupling of cardiac systolic and diastolic function during times of acute stress. Adenosine may increase compliance by decreasing tension in smooth muscle, and its associated series elastic elements. When the heart ejects blood at a rate and volume that matches the capability of the arterial system to receive it, both cardiovascular performance and cardiac energetics are believed to be optimal (VA coupling ratio =1.0) (see Table 1). 
"Vasoactive drugs alter smooth muscle tone not only in arterial resistance vessels, but also in large conduit arteries ... The resultant changes in smooth muscle tone alter both conduit vessel size and stiffness and hence influence pulsatile components of left ventricular afterload" (Bank, 1997).

Bank further reported that the effect to nitroglycerin, an NO donor commonly used to treat myocardial ischemia in humans by increasing coronary blood flow, also decreased pulse wave velocity and increased arterial compliance from its dilation properties and effects on heart chamber geometry (Bank and Kaiser, 1998). In multicellular organisms, evolution may have selected adenosine, nitric oxide and other modulators, to provide optimal oxygen and nutrient transfer along vascular branching networks from the lung, heart, large arteries and arterioles, capillaries to respiring mitochondria (Dobson, 2003).

Additional support for the adenosine VA coupling hypothesis comes from adenosine's widespread distribution throughout the cardiovascular system, and long recognized linkage between transitioning from aerobic to anaerobic metabolism, AMP production and adenosine formation (see Figure 2A). Since adenosine has a very short half-life (secs), its ability to be rapidly activate and inactivate may constitute a high-gain feedback control system between the heart and conduit arteries. Adenosine levels have been shown to change in heart muscle during a single cardiac cycle, with higher levels being produced during systole than diastole, indicating rapid metabolism of adenosine (Thompson et al., 1980). In addition, adenosine depresses heart pacemaker activity (negative chronotropic effect), decreases atrial and ventricle contractility (negative inotropic effect), depresses cardiac automaticity (dromotropic effect), and decreases heart diastolic stiffness (lusitropic effect) (Figure 2A) (Vinten-Johansen et al., 1999; Jacobson and Gao, 2006; Mustafa et al., 2009; Headrick et al., 2013; Minic et al., 2015).

Perhaps the most compelling set of human data supporting a role for adenosine in VA coupling comes from Wong and colleagues who reported a relationship between increased aortic stiffness, lower VA coupling and lower coronary blood flow in patients with stable angina undergoing an adenosine stress test (Wong et al., 2010). Unfortunately, these authors did not comment on a possible adenosine spatial-temporal link between arterial stiffness and coronary perfusion, presumably because it was a clinical diagnostic test. Leung and colleagues also showed in humans that aortic stiffness affected coronary blood flow during percutaneous coronary intervention (PCI), and that a more compliant aorta was associated with a greater improvement in adenosine-induced increases in coronary blood flow compared to patients which had a stiffer aorta (Leung et al., 2006). Pagliaro and colleagues also showed in dogs that a combination of low dose adenosine and enhanced perfusion pulsatility markedly increased coronary blood flow by mechanisms involving adenosine receptors, $\mathrm{NO}$ and $\mathrm{K}_{\mathrm{ATP}}$ channels, and possibly other purinergic receptors (Pagliaro et al., 1999; Kass, 2005; Burnstock and Ralevic, 2013). Adenosine has also been reported to dilate the vasa vasorum that supplies blood to the aortic media (Heistad et al., 1978), which may also influence compliance. Future studies are required to extend these clinical and experimental observations, and examine if the effects of adenosine (and NO) in large elastic arteries change in concentration under different cardiac workload conditions. If changes are found they may reflect differential activation of adenosine receptor subtypes $\left(\mathrm{A}_{1}, \mathrm{~A}_{2 \mathrm{~A}}, \mathrm{~A}_{2 \mathrm{~B}}\right.$, and $\mathrm{A}_{3}$ ) (Figure 2A). Interestingly, Leal and colleagues reported that the rat abdominal aorta had 35-times higher abundance of the $\mathrm{A}_{3}$ receptor subtype than in a muscular tail artery, and a significantly lower abundance of $A_{1}$ and $A_{2 A}$ receptors in the conduit (Leal et al., 2008), which may imply different functional roles (Figures $2 \mathbf{A}, \mathbf{B}$ ).

Finally, since the heart and elastic and geometric properties of conduit arteries are important predictors of aging and disease progression, the adenosine VA hypothesis may offer a new conceptual scheme for future research and therapeutic intervention. Questions include whether adenosine levels change in large conduit arteries and along their length in healthy vs. older patients with hypertension, diabetes mellitus, obesity, coronary artery disease and/or heart failure (AlGhatrif and Lakatta, 2015; Yurdagul et al., 2016). Further, do these changes correlate with changes in myocardial perfusion, VA coupling and wall stiffness? Indeed, progressive vessel wall stiffening, and microcirculatory endothelial dysfunction has been reported along the wall of the thoracic aorta, which precedes hypertension, diabetes and cardiovascular diseases, including aortic aneurysms (Erbel and Eggebrecht, 2006; Huveneers et al., 2015). Recently the VA coupling ratio was found to be profoundly decreased in a population of centenarians without overt cardiovascular disease, particularly in women (Sonaglioni et al., 2017), highlighting again the importance of understanding the changes between heart, aortic compliance and vascular aging. In conclusion, we propose that adenosine may play an important role in maintaining aortic wall integrity and compliance for optimal VA coupling, coronary perfusion and downstream regulation of tissue blood flow and oxygenation. This hypothesis warrants further testing.

\section{AUTHOR CONTRIBUTIONS}

All authors listed, have made substantial, direct and intellectual contribution to the work, and approved it for publication.

\section{FUNDING}

Research support was obtained from internal research funds to GD from College of Medicine and Dentistry, James Cook University.

\section{ACKNOWLEDGMENTS}

The authors would like to thank the College of Medicine and Dentistry, James Cook University for support of the project, and to the Australian Government Endeavour Scholarship to AA to support his academic stay at JCU. The authors would also like to thank Dr. Jodie Morris for critically reading the manuscript and editorial assistance. 


\section{REFERENCES}

AlGhatrif, M., and Lakatta, E. G. (2015). The conundrum of arterial stiffness, elevated blood pressure, and aging. Curr. Hypertens. Rep. 17:12. doi: 10.1007/s11906-014-0523-Z

Arsyad, A., and Dobson, G. P. (2016). Adenosine relaxation in isolated rat aortic rings and possible roles of smooth muscle Kv channels, KATP channels and A2a receptors. BMC Pharmacol. Toxicol. 17:23. doi: 10.1186/s40360-016-0067-8

Bank, A. J. (1997). Physiologic aspects of drug therapy and large artery elastic properties. Vasc. Med. 2, 44-50. doi: 10.1177/1358863X9700200107

Bank, A. J., and Kaiser, D. R. (1998). Smooth muscle relaxation: effects on arterial compliance, distensibility, elastic modulus, and pulse wave velocity. Hypertension 32, 356-359. doi: 10.1161/01.HYP.32.2.356

Behringer, E. (2017). Calcium and electrical signaling in arterial endothelial tubes: new insights into cellular physiology and cardiovascular function. Microcirculation 24, 1-12. doi: 10.1111/micc. 12328

Bellien, J., Favre, J., Iacob, M., Gao, J., Thuillez, C., Richard, V., et al. (2010). Arterial stiffness is regulated by nitric oxide and endothelium-derived hyperpolarizing factor during changes in blood flow in humans. Hypertension 55, 674-680. doi: 10.1161/HYPERTENSIONAHA.109.142190

Berne, R. M. (1963). Cardiac nucleotides in hypoxia: possible role in regulation of coronary blood flow. Am. J. Physiol. 204, 317-322.

Berne, R. M. (1980). The role of adenosine in the regulation of coronary blood flow. Circ. Res. 47, 807-813. doi: 10.1161/01.RES.47.6.807

Berne, R. M. (1998). BY CHOICE OR BY CHANCE: factors that influenced my life and career. Annu. Rev. Physiol. 60, 1-18. doi: 10.1146/annurev.physiol.60.1.1

Bouvrain, Y., and Levy, B. (1981). "Windkessel" and coronary debit. Arch. Mal. Coeur Vaiss. 74, 635-639.

Burnstock, G., and Ralevic, V. (2013). Purinergic signaling and blood vessels in health and disease. Pharmacol. Rev. 66, 102-192. doi: 10.1124/pr.113.008029

Chan, E. S., and Cronstein, B. N. (2010). Adenosine in fibrosis. Mod. Rheumatol. 20, 114-122. doi: 10.3109/s10165-009-0251-4

Chantler, P. D., Lakatta, E. G., and Najjar, S. S. (2008). Arterial-ventricular coupling: mechanistic insights into cardiovascular performance at rest and during exercise. J. Appl. Physiol. 105, 1342-1351. doi: 10.1152/japplphysiol.90600.2008

Chen, C. H., Fetics, B., Nevo, E., Rochitte, C. E., Chiou, K. R., Ding, P. A., et al. (2001). Noninvasive single-beat determination of left ventricular end-systolic elastance in humans. J. Am. Coll. Cardiol. 38, 2028-2034. doi: 10.1016/S0735-1097(01)01651-5

Collis, M. G. (1989). The vasodilator role of adenosine. Pharmac. Ther. 41, 143-162. doi: 10.1016/0163-7258(89)90104-6

Dobson, G. P. (2003). On being the right size: heart design, mitochondrial efficiency, and lifespan potential. Clin. Exp. Pharm. Physiol. 30, 590-597. doi: 10.1046/j.1440-1681.2003.03876.x

Drury, A. N., and Szent-Gyorgyi, A. (1929). The physiological activity oif adenine compounds with especial reference to their action upon the mammalian heart. J. Physiol. 68, 213-237. doi: 10.1113/jphysiol.1929.sp002608

Duncker, D. J., and Bache, R. J. (2008). Regulation of coronary blood flow during exercise. Physiol. Rev. 88, 1009-1086. doi: 10.1152/physrev.00045.2006

Erbel, R., and Eggebrecht, H. (2006). Aortic dimensions and the risk of dissection. Heart 92, 137-142. doi: 10.1136/hrt.2004.055111

Ernens, I., Bousquenaud, M., Lenoir, B., Devaux, Y., and Wagner, D. R. (2015). Adenosine stimulates angiogenesis by up-regulating production of thrombospondin-1 by macrophages. J. Leukocyte Biol. 97, 9-18. doi: 10.1189/jlb.3HI0514-249RR

Feigl, E. O. (2004). Berne's adenosine hypothesis of coronary blood flow control. Am. J. Physiol. Heart Circ. Physiol. 287, H1891-H1894. doi: 10.1152/classicessays.00003.2004

Félétou, M. (2016). Endothelium-dependent hyperpolarization and endothelial dysfunction. J. Cardiovasc. Pharmacol. 67, 373-387. doi: 10.1097/FJC.0000000000000346

Félétou, M., and Vanhoutte, P. M. (2007). Endothelium-dependent hyperpolarizations: past beliefs and present facts. Ann. Med. 39, 495-516. doi: 10.1080/07853890701491000

Feliciano, L., and Henning, R. J. (1999). Coronary artery blood flow: physiologic and pathophysiologic regulation. Clin. Cardiol. 22, 775-786. doi: $10.1002 /$ clc.4960221205
Fredholm, B. B., IJzerman, A. P., Jacobson, K. A., Klotz, K. N., and Linden, J. (2001). International union of pharmacology. XXV. Nomenclature and classification of adenosine receptors. Pharmacol Rev. 53, 527-552.

Furchgott, R. F. (1983). Role of endothelium in responses of vascular smooth muscle. Circ. Res. 53, 557-573. doi: 10.1161/01.RES.53.5.557

Guarracino, F., Baldassarri, R., and Pinsky, M. R. (2013). Ventriculo-arterial decoupling in acutely altered hemodynamic states. Crit. Care 17, 213-220. doi: $10.1186 /$ cc12522

Hasko, G., and Cronstein, B. N. (2004). Adenosine: an endogenous regulator of innate immunity. Trends Immunol. 25, 33-39. doi: 10.1016/j.it.2003.11.003

Headrick, J. P., Ashton, K. J., Rose'meyer, R. B., and Peart, J. N. (2013). Cardiovascular adenosine receptors: expression, actions and interactions. Pharmacol. Ther. 140, 92-111. doi: 10.1016/j.pharmthera.2013.06.002

Headrick, J. P., and Berne, R. M. (1990). Endothelium-dependent and independent relaxations to adenosine in guinea pig aorta. Am. J. Physiol. 259(1 Pt 2), H62-H67.

Heistad, D. D., Marcus, M. L., Law, E. G., Armstrong, M. L., Ehrhardt, J. C., and Abboud, F. M. (1978). Regulation of blood flow to the aortic media in dogs. J. Clin. Invest. 62, 133-140. doi: 10.1172/JCI109097

Huveneers, S., Daemen, M. J., and Hordijk, P. L. (2015). Between Rho(k) and a hard place: the relation between vessel wall stiffness, endothelial contractility, and cardiovascular disease. Circ. Res. 116, 895-908. doi: 10.1161/CIRCRESAHA.116.305720

Jacobson, I., and Gao, Z.-G. (2006). Adenosine receptors as therapeutic targets. Nat. Rev. 5, 247-264. doi: 10.1038/nrd1983

Jonker, F. H., van Keulen, J. W., Schlosser, F. J., Indes, J. E., Moll, F. L., Verhagen, H. J., et al. (2011). Thoracic aortic pulsatility decreases during hypovolemic shock: implications for stent-graft sizing. J. Endovasc. Ther. 18, 491-496. doi: $10.1583 / 10-3374.1$

Kass, D. A. (2005). Ventricular arterial stiffening: integrating the pathophysiology. Hypertension 46, 185-193. doi: 10.1161/01.HYP.0000168053. 34306.d4

Leal, S., Sá, C., Gonçalves, J., Fresco, P., and Diniz, C. (2008). Immunohistochemical characterization of adenosine receptors in rat aorta and tail arteries. Microsc. Res. Tech. 71, 703-709. doi: 10.1002/jemt.20609

Leung, M. C. H., Meredith, I. T., and Cameron, J. D. (2006). Aortic stiffness affects the coronary blood flow response to percutaneous coronary intervention. Am. J. Physiol. Heart Circ. Physiol. 290, H624-H630. doi: 10.1152/ajpheart.00380.2005

Lewis, C. D., and Hourani, S. M. (1997). Involvement of functional antagonism in the effects of adenosine antagonists and L-NAME in the rat isolated heart. Gen. Pharmacol. 29, 421-427. doi: 10.1016/S0306-3623(96)00466-1

Linden, J. (2001). Molecular approach to adenosine receptors: receptor-mediated mechanisms of tissue protection. Ann. Rev. Pharmacol. Toxicol. 41, 775-787. doi: 10.1146/annurev.pharmtox.41.1.775

London, G. M. (2005). Role of arterial wall properties in the pathogenesis of systolic hypertension. Am. J. Hypertens. 18(1 Pt 2), 19S-22S. doi: 10.1016/j.amjhyper.2004.10.001

Mangoni, A. A., Mircoli, L., Giannattasio, C., Ferrari, A. U., and Mancia, G. (1996). Heart rate-dependence of arterial distensibility in vivo. J. Hypertens. 14, 897-901. doi: 10.1097/00004872-19960700000013

Marti, C. N., Gheorghiade, M., Kalogeropoulos, A. P., Georgiopoulou, V. V., Quyyumi, A. A., and Butler, J. (2012). Endothelial dysfunction, arterial stiffness, and heart failure. J. Am. Coll. Cardiol. 60, 1455-1469. doi: 10.1016/j.jacc.2011.11.082

Minic, Z., O'Leary, D. S., and Scislo, T. J. (2015). NTS adenosine A2a receptors inhibit the cardiopulmonary chemoreflex control of regional sympathetic outputs via a GABAergic mechanism. Am. J. Physiol. Heart Circ. Physiol. 309, H185-H197. doi: 10.1152/ajpheart.00838.2014

Mustafa, S. J., Morrison, R. R., Teng, B., and Pelleg, A. (2009). “Adenosine receptors and the heart: role in regulation of coronary blood flow and cardiac electrophysiology," in Adenosine Receptors in Health and Disease: Handbook of Experimental Pharmacology, eds C. N. Wilson and S. Mustafa (Berlin; Heidelberg: Springer-Verlag), 160-188.

Najjar, S. S., Schulman, S. P., Gerstenblith, G., Fleg, J. L., Kass, D. A., O’Connor, F., et al. (2004). Age and gender affect ventricular-vascular coupling during aerobic exercise. J. Am. Coll. Cardiol. 44, 611-617. doi: 10.1016/j.jacc.2004.04.041 
Ooi, H., Chung, W., and Biolo, A. (2008). Arterial stiffness and vascular load in heart failure. Congest. Heart Fail. 14, 31-36. doi: 10.1111/j.1751-7133.2008.07210.x

Pagliaro, P., Senzaki, H., Paolocci, N., Isoda, T., Sunagawa, G., Recchia, F. A., et al. (1999). Specificity of synergistic coronary flow enhancement by adenosine and pulsatile perfusion in the dog. J. Physiol. 520(Pt 1), 271-280. doi: 10.1111/j.1469-7793.1999.00271.x

Ponnoth, D. S., Sanjani, M. S., Ledent, C., Roush, K., Krahn, T., and Mustafa, S. J. (2009). Absence of adenosine-mediated aortic relaxation in A(2A) adenosine receptor knockout mice. Am. J. Physiol. Heart Circ. Physiol. 297, H1655-H1660. doi: 10.1152/ajpheart.00192.2009

Quillon, A., Fromy, B., and Debret, R. (2015). Endothelium microenvironment sensing leading to nitric oxide mediated vasodilation: a review of nervous and biomechanical signals. Nitric Oxide 45, 20-26. doi: 10.1016/j.niox.2015.01.006

Quinn, U., Tomlinson, L. A., and Cockcroft, J. R. (2012). Arterial stiffness. JRSM Cardiovasc. Dis. 1:cvd.2012.012024. doi: 10.1258/cvd.2012.012024

Ray, C., and Marshall, J. (2006). The cellular mechanism by which adenosine evokes release of nitric oxide from rat aortic endothelium. J. Physiol. 570(Pt 1), 85-96. doi: 10.1113/jphysiol.2005.099390

Shimokawa, H., and Godo, S. (2016). Diverse functions of endothelial NO synthases system: NO and EDH. J. Cardiovasc. Pharmacol. 67, 361-366. doi: 10.1097/FJC.0000000000000348

Sonaglioni, A., Baravelli, M., Lombardo, M., Sommese, C., Anzà, C., Kirk, J. A., et al. (2017). Ventricular-arterial coupling in centenarians without cardiovascular diseases. Aging Clin. Exp. Res. doi: 10.1007/s40520-017-0783-y. [Epub ahead of print].

Steppan, J., Barodka, V., Berkowitz, D. E., and Nyhan, D. (2011). Vascular stiffness and increased pulse pressure in the aging cardiovascular system. Cardiol. Res. Pract. 2011:263585. doi: 10.4061/2011/263585

Suga, H., Goto, Y., Kawaguchi, O., Hata, K., Takasago, T., Saeki, T. W., et al. (1993). "Ventricular perspective on efficiency," in Myocardial Optimization and Efficiency, Evolutionary Aspects and Philosophy of Science Considerations, eds D. Burkhoff, J. Schaefer, K. Schaffner, and D. T. Yue (New York, NY: Springer-Verlag), 43-65.

Tabrizchi, R., and Bedi, S. (2001). Pharmacology of adenosine receptors in the vasculature. Pharmac. Ther. 91, 133-147. doi: 10.1016/S0163-7258(01)00152-8

Thompson, C. I., Rumo, R., and Berne, R. M. (1980). Changes in adenosine and glycogen phosphorylase activity during the cardiac cycle. Am. J. Physiol. 238, H389-398.
Vecchio, E. A., White, P. J., and May, L. T. (2017). Targeting adenosine receptors for the treatment of cardiac fibrosis. Front. Pharmacol. 8:243. doi: 10.3389/fphar.2017.00243

Vinten-Johansen, J., Thourani, V. H., Ronson, R. S., Jordan, J. E., Zhao, Z. Q., Nakamura, M., et al. (1999). Broad-spectrum cardioprotection with adenosine. Ann. Thorac. Surg. 68, 1942-1948. doi: 10.1016/S0003-4975(99) 01018-8

Vinten-Johansen, J., Zhao, Z. Q., Jiang, R., Zatta, A. J., and Dobson, G. P. (2007). Preconditioning and postconditioning: innate cardioprotection from ischemia-reperfusion injury. J. Appl. Physiol. 103, 1441-1448. doi: 10.1152/japplphysiol.00642.2007

Wilkinson, I. B., Qasem, A., McEniery, C. M., Webb, D. J., Avolio, A. P., and Cockcroft, J. R. (2002). Nitric oxide regulates local arterial distensibility in vivo. Circulation 105, 213-217. doi: 10.1161/hc0202.101970

Wong, D., Chew, D., Cameron, J., Nelson, A., Meredith, I., Worthley, S., et al. (2010). Arterial stiffness predicts myocardial perfusion reserve: An adenosine stress cardiac magnetic resonance study. Heart Lung Circul. 19(Suppl. 2), S11. doi: 10.1016/j.hlc.2010.06.688

Yurdagul, A. J., Finney, A. C., Woolard, M. D., and Orr, A. W. (2016). The arterial microenvironment: the where and why of atherosclerosis. Biochem. J. 473, 1281-1295. doi: 10.1042/BJ20150844

Zhipeng, H., Zhiwei, W., Lilei, Y., Hao, Z., Hongbing, W., Zongli, R., et al. (2014). Sympathetic hyperactivity and aortic sympathetic nerve sprouting in patients with thoracic aortic dissection. Ann. Vasc. Surg. 28, 1243-1248. doi: 10.1016/j.avsg.2013.11.016

Zieman, S. J., Melenovsky, V., and Kass, D. A. (2005). Mechanisms, pathophysiology, and therapy of arterial stiffness. Arterioscler. Thromb. Vasc. Biol. 25, 932-943. doi: 10.1161/01.ATV.0000160548.78317.29

Conflict of Interest Statement: The authors declare that the research was conducted in the absence of any commercial or financial relationships that could be construed as a potential conflict of interest.

Copyright (c) 2017 Dobson, Arsyad and Letson. This is an open-access article distributed under the terms of the Creative Commons Attribution License (CC BY). The use, distribution or reproduction in other forums is permitted, provided the original author(s) or licensor are credited and that the original publication in this journal is cited, in accordance with accepted academic practice. No use, distribution or reproduction is permitted which does not comply with these terms. 